\title{
CORRESPONDENCE
}

\section{Return to work}

Felicity C Edwards, DM

Ipecacuanha as an emetic for adults

S M Gibb, and others............ 1474

Babies in the front seat

Anne Seymour, FRCS.

An epidural service

J S Crawford, FFARCS

Bromocriptine and uterine neoplasia

M S Rose, MrCPaTH; H S Jacobs, MD, and

J D Hutton, MRCOG; G M Besser, FRCP. . 1475

Eating bracken shoots

I Antice Evans, PHD, and W C Evans, PHD. . 1476

Surgeons and money

K McPherson, PHD . ............. 1476

Dietary cholesterol and atherosclerosis

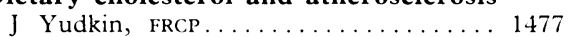

Treating dissenters

D Shaw, FRCPSYCH; C H Maycock, MB.. 1477

Pneumoconiosis and chronic bronchitis

D C F Muir, FRCP, and others.

Oestrogens for menopausal flushing

Jean K M Coope, MB, and L Poller, FRCPATH.

Ischaemic colitis and drug abuse

R S J Briggs, MRCP, and others......... 1478

ECT and the media

$\mathrm{J} F$ Anderson.
Susceptibility of bacteroides to

noxythiolin

R H George, MRCPATH, and D E Healing,

Drinking behaviour

H G Kinnell, MRCP.

Cimetidine and gastric ulcer healing

K G Jensen, $M D$, and others.........

Depression in men and women

treatment

D G Limb, MRCOG

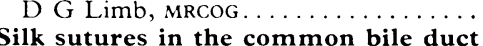

M H Gough, FRCS

Anaphylactoid reactions to dextran 70

G A H Heaney, FFARCSI.

G A H Heaney, FFARCSI. ..

Lichen-planus-like eruption: a marker

for chronic graft-versus-host reaction

J H Saurat, MD, and Eliane Gluckman, MD 1480

Adverse reactions to intravenous

thiopentone

H J E Lewi, MB, and T V Taylor, FrCS . . . 1480

Bell's palsy and herpes simplex

P Grout, MRCGP.

Saliva carbamazepine levels in children

G W Rylance, MRCP, and others....... 1481

Shortage of anaesthetists

C A N Jarvis, MB, DA. .

1480
The other handicap: brightness

F G Herman, FRCPATH

"Curing" minor illness in general

practice

P Catlin, MB

Primary care in Kenya

J M Gray...............

Changing the FRCS exam

A G Graham, FRCSED. medicine

The medical manpower debate

L C A Watson, FRCP ; D F H Guèret Wardle,

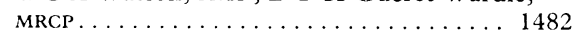

Functional budgeting

A Smith, MRCPGLAS

Assessment for invalidity pensions

I G Mowat, MRCGP............. 1483

Confidentiality

C Lipp, LRCP

Requirements for temporary registration

M R Draper, BA................ 1483

Points from letters Varus and valgus (A P Millar); Oust the louse ( $\mathrm{H}$ de Glanville); Increases in plasma prostaglandin after vaginal examination and amniotomy ( $\mathrm{R}$ A Wikner) Of molluscs and men (J J C Cormack).... 1483
Correspondents are urged to write briefly so that readers may be offered as wide a selection of letters as possible. So many are being received that the omission of some is inevitable. Letters should be signed personally by all their authors.

\section{Return to work}

SIR,-Further to recent discussions in your journal on the subject of return to work I would like to reply briefly to Professor R C B Aitken's letter (12 November, p 1284).

I am glad that Professor Aitken agrees with my contention (15 October, p 1027) that return to work is a most important criterion of outcome and I have stressed the importance of work status being included, particularly where expensive and time-consuming treatments are being evaluated, in any long-term follow-up study. We have been impressed by the positive attitude taken by the many clinical departments with which we have been cooperating, and the extent to which consultants do bear this aspect of their patients' adjustment in mind.

The Employment Medical Advisory Service (EMAS) provides part-time medical and fulltime nursing services to 24 employment rehabilitation centres in Great Britain which are managed by the Employment Service Agency (ESA). EMAS is also providing medical advice to the Employment Rehabilitation Research Centre, whose purpose is to evaluate the effectiveness of employment rehabilitation. This research centre is managed by the ESA and is responsible to the Manpower Services Commission.

We would like to think, although ours is a small and specialist service numbering only the equivalent of 100 full-time doctors throughout Great Britain, that wherever and whenever we can we do provide and encourage specific links between the employment services, the NHS, and industry. We feel that gaining employment for disabled people is much more a problem of close contact with industry and with the personnel and occupational health staff concerned than of an exact knowledge of prognosis in various medical conditions. The ideal is obviously a happy mean-a disablement resettlement officer (DRO) should have a certain standard of knowledge of medical and psychiatric prognosis (and this is what the new national DRO training centre is aiming to provide, with EMAS advice) and should also have extensive involvement with industry (and this is the aim of ESA's recent policy with regard to their DRO service)

Finally, both Drs D A Brewerton and P J R Nichols (15 October, p 1006) and Professor Aitken ignore the fact that industry itself contributes in a major way to placement of employees. There are several major industries in Britain which take an especial interest in rehabilitation and many other industries also have occupational health services, one of whose main functions is to consider the effects of illness or injury on their employees' work. In such industries, and in the several group occupational health services, medical and nursing staff are daily performing such assessments, many of which will result in placing employees in modified work. Because of the nature of our organisation EMAS maintains very close links with occupational health services throughout the country and through the Society of Occupational Medicine.

Felicity EDWARds

Employment Medical Advisory Service, Health and Safety Executive, Birmingham

\section{Ipecacuanha as an emetic for adults}

SIR,-We wish to take issue with your recent leading article (15 October, p 977) "Emetics for acute poisoning-treatment or hazard?" which concluded with the statement that "for adults there is as yet no convincing evidence on the efficacy of syrup of ipecacuanha, and gastric lavage remains the treatment of choice until further studies suggest to the contrary."

We have recently reported' on a trial of the efficacy of ipecacuanha syrup as an emetic in adult patients presenting to the Royal Perth Hospital Emergency Department with a diagnosis of accidental or intentional poisoning. Patients were given either a $15-\mathrm{ml}(\mathrm{n}=34)$ or a 30-ml dose $(\mathrm{n}=33)$ of syrup of ipecacuanha APF (Australian Pharmaceutical Formulary; $0 \cdot 14 \% \mathrm{w} / \mathrm{v}$ total alkaloids) together with a 200-ml draught of water. Patients who did not vomit within $30 \mathrm{~min}$ of the first dose were given a second dose of equivalent size and a second 200-ml draught of water. At the 15-ml dose level $68 \%$ of patients vomited after the first dose (mean time to vomit, $17 \mathrm{~min}$ ) and a further $20 \%$ vomited after a second dose of syrup (mean time to vomit, $45 \mathrm{~min}$ after first dose), making a total response in this group of $88 \%$. In the $30-\mathrm{ml}$ dose group $76 \%$ of patients vomited after the first dose of 
ipecacuanha (mean time to vomit, $17 \mathrm{~min}$ ) and a further $20 \%$, vomited after the second dose of the syrup (mean time to vomit, $36 \mathrm{~min}$ after first dose), making a total response of $96 \%$ in this group. There was no significant difference in the proportion of patients vomiting between the 15- and 30-ml dose groups.

Our results indicate that syrup of ipecacuanha is indeed an effective treatment for poisoning in adults and must be regarded as a useful and often more convenient and safer alternative to gastric lavage. It should, however, be emphasised that ipecacuanha syrup is contraindicated for comatose patients and also for those patients who have ingested corrosive substances or petroleum distillates.

Stuart M Gibi

Department of Pharmacy

Royal Perth Hospital

R W UNSWORTH

Delta West Pty Ltd,

Kewdale, W Australia

\section{KenNeth F Ilett}

Department of Pharmacology,

University of Western

Ilett, K F, Gibb, S M, and Unsworth, R W, Medical fournal of Australia, 1977, 2, 91.

\section{Babies in the front seat}

SIR,-I was disturbed to read in the newspaper that when returning home from hospital Princess Anne sat in the front seat of the car holding her baby in her arms. I think it is now accepted among accident surgeons that it is extremely dangerous for small children to be carried on the knee or in the arms of the frontseat passenger.

When I worked as a surgical registrar whose work involved a maternity unit I found that many proud fathers collecting their wives in the family car had never been advised that the person holding the baby should, if possible, sit in the back of the car. I wonder whether our obstetric colleagues might feel that this was an item of health education and accident prevention which they might undertake.

\section{A SEymour}

Accident and Emergency

Department,

Ingham Infirmary,
South Shields, Tyne and wear

\section{An epidural service}

SIR,-I have followed with interest the correspondence on this subject ( 3 September, p 644; 24 September, pp 831-2; 8 October, p 958; 29 October, p 1148). During the pas three years I have been responsible for the supervision of the training of 27 obstetricians (mainly from elsewhere in the UK or from continental Europe) in the practice of initiation and maintenance of continuous lumbar epidural block analgesia for labour and delivery and I am quite happy to continue to provide this facility.

The system whereby the obstetrician provides and is responsible for an epidural service in his unit is, in my view, perfectly acceptable in the event that some simple requirements have been met. Certainly the obstetrician should be relatively well competent in the field and this does not imply simply that he has gained facility in the introduction of a cannula into the epidural space. It is for this reason that I insist that doctors who come "on attachment" spend at least four weeks full time in this hospital so that they can gain a reasonable adequacy of experience of the range of responses -anaesthetic and obstetric, during labour and post partum-which may be exhibited by a community of patients. Secondly, it must always be possible to obtain anaesthetic aid within 10 minutes of initiation of the request-this is no reflective of the specific demands evoked by an epidural service; were I an obstetrician I would refuse to conduct a practice in Britain or elsewhere in the developed world in which such a facility were not available. The evisaged situation, therefore, is one in which the anaesthetic staffing is insufficient to sustain an epidural service but is necessarily able to respond to calls for general anaesthesia. In poin of fact introduction of an epidural service will reduce the latter category of demand virtually to cases of caesarean section alone. For example, the accompanying table shows the numbers of general anaesthetics administered in this hospital for the procedures indicated when an epidural service was in its infancy and when it achieved its current intensity.

\begin{tabular}{c|c|c}
\hline Year & $\begin{array}{c}\text { Forceps, breech, } \\
\text { multiple } \\
\text { pregnancy }\end{array}$ & $\begin{array}{c}\text { Removal of } \\
\text { retained } \\
\text { placenta }\end{array}$ \\
\hline 1969 & 79 & 89 \\
1970 & 56 & 57 \\
1976 & 2 & 22 \\
$1977(1012)$ & 3 & 7
\end{tabular}

It must be conceded that although this chang reflects mainly the impact of an epidural service, it also in part is the result of our increasingly frequen application of the admirable technique of spinal analgesia for those patients who do not have an epidural in situ when the first stage of labour draws to a close, and this also can be provided by an obstetrician.

I am unconvinced by the expressions of alarm regarding the hazards of respiratory paralysis and profound hypotension. We have provided an epidural for close on 13000 labouring patients and although in a handful of cases the sensory block (extradural) has extended to $\mathrm{T} 2$ and on three or four occasions there has undoubtedly been an inadvertent injection of bupivacaine into the cerebrospinal fluid (with, twice, extension of the block to a similar level) we have never required to assist a patient's ventilation, much less to pass an endotracheal tube. Strangely enough, despite the postulated extent of sympathetic block, although hypotension has been marked on a few occasion it has never been profound and has responded satisfactorily to the rapid infusion of Hartmann's solution (plus, on two occasions, a small dose of ephedrine). No evidence of fetal harm has resulted from these episodes.

Even should profound respiratory paralysis result from extradural or accidental intrathecal injection I cannot accept that tragedy would be the outcome in a competently administered obstetric unit. The onset is not abrupt and evidence of the undesirable spread of block would become apparent over the course of several minutesduring which period, if anaesthetic help were considered desirable, it would be requested as for a case of prolapsed cord or severe haemorrhage. Active vomiting could hardly be a problem as the abdominal and lower intercostal muscles and the diaphragm would be flaccid. Equally I fail to understand why passive regurgitation should be considered a likely resultant of total block. In this context it should be noted that in a well-conducted obstetric unit (the essential prerequisite of the introduction of an epidural service) the appropriate dietary regimen and antacid prophylaxis will be in peration. In such a service, too, the patient will be either lying laterally, tilted laterally, or reclining against a back-rest. Assisted ventilation with bag and mask, or even by mouth to mouth, should not be beyond the compass of any doctor or nurse. In the unlikely event that endotracheal intubation is deemed to be necessary either of these measure should suffice to support the patient until the anaesthetist arrives. However, we do ensure that our obstetric trainees have some competence in endotracheal intubation and I cannot accept that the posture of the patient need render the procedure more difficult. A patient tilted on a wedge for caesarean section has proved to be no more difficult to intubate than did those we used to keep supine.

In summary, I shall continue fully to support the arrangement whereby obstetricians can initiate and maintain an epidural for labour and delivery-it is part of the spectrum of what I envisage as a sliding scale of investments. If the obstetric unit is blessed with a powerful anaesthetic establishment doubtless most epidurals will be administered by anaesthetists; if the competent anaesthetists are so few that they can respond only to emergency calls for general anaesthesia the epidural load will be borne by those obstetricians who have undergone the necessary training and desire to give their patients a painless labour.

J SELWyn CRAWford

Birmingham Maternity Hospital, Queen Flizabeth Medical Centre,
Birmingham

\section{Bromocriptine and uterine neoplasia}

SIR,-The argument of Professor G M Besser and others (1 October, p 868) is difficult to follow. A 100-week study has shown that a proportion of rats on bromocriptine develop endometrial hyperplasia and malignant tumours. We are not informed about numbers. Examining 88 women, $60 \%$ of whom have received bromocriptine for less than two years and presumably not long ago, the authors have observed no hyperplastic or neoplastic lesions in the genital tract. From this evidence they feel qualified to suggest that "bromocriptine may indeed protect against the possible adverse effects of prolonged unopposed actions of oestrogens." They conclude, however, that "it is advisable that patients on long-term treatment should undergo gynaecological assessment ... every year during treatment." Why?

Isn't this all rather tenuous evidence one way or the other?

M S Rose

\section{St George's Hospital,}

London SW 17

SIR,-Bromocriptine is now the drug of choice for suppression of puerperal and inappropriate hyperprolactinaemia, so it is distressing to find that an unknown proportion of rats treated with it for 100 weeks have developed cancer of the endometrium (Griffith, R W, personal communication cited by Professor G M Besser and others (1 October, p 868)). Professor Besser and his colleagues state that the rat is a poor endocrine model of the human, but their report of gynaecological investigations of 88 women treated with bromocriptine hardly assesses the drug's potential carcinogenicity.

The term uterine neoplasia usually encompasses both carcinoma of the cervix and carcinoma of the body of the uterus (endometrial carcinoma). There is no evidence to suggest a hormonal aetiology of cervical cancer and apparently this condition did not occur in the rats given bromocriptine. Thus, despite the title of their paper, the study by Professor Besser and his colleagues presumably concerns 